\title{
Redox reaction in two-dimensional porous coordination polymers based on ferrocenedicarboxylates.
}

\section{$\operatorname{AUTHOR}(\mathrm{S}):$}

Hirai, Kenji; Uehara, Hiromitsu; Kitagawa, Susumu; Furukawa, Shuhei

\section{CITATION:}

Hirai, Kenji ... [et al]. Redox reaction in two-dimensional porous coordination polymers based on ferrocenedicarboxylates.. Dalton transactions 2012, 41(14): 3924-3927

\section{ISSUE DATE:}

2012-02-29

URL:

http://hdl.handle.net/2433/172095

\section{RIGHT:}

(c) The Royal Society of Chemistry 2012.; この論文は出版社版でありま せん。引用の際には出版社版をご確認じ利用ください。; This is not the published version. Please cite only the published version. 


\title{
Redox reaction in two-dimensional porous coordination polymers based on ferrocenedicarboxylates
}

\author{
Kenji Hirai, ${ }^{a}$ Hiromitsu Uehara, ${ }^{b}$ Susumu Kitagawa, ${ }^{a, b, c}$ and Shuhei Furukawa* ${ }^{b, c}$ \\ Received (in $X X X, X X X)$ Xth $X X X X X X X X X 20 X X$, Accepted Xth $X X X X X X X X X 20 X X$ \\ DOI: 10.1039/b000000x
}

A series of 1,1'-ferrocenedicarboxylate-based twodimensional porous coordination polymers were synthesized by incorporating different diamine coligands. These compounds immobilized on electrodes, exhibited reversible 10 redox reactions, arising from ferrocenyl moiety.

Porous coordination polymers (PCPs), assembled from metal ions and organic ligands, are an interesting class of crystalline materials ${ }^{1}$. They have been extensively studied for applications in gas storage ${ }^{2}$, separation ${ }^{3}$ and chemical sensing ${ }^{4}$. Compared with 15 these porous properties, only a few studies on the electronic properties of the frameworks have been reported ${ }^{5}$. The synergetic collaboration between the electronic properties of the framework and the intrinsic porous properties has led to new applications of PCPs in a wide range of important fields. In particular, a redox20 active PCP may be useful material for electrochemical applications such as ion storage ${ }^{6}$ or electrocatalysis ${ }^{7}$. The key to successful implementation is not only to construct the redoxactive framework itself, but also to hybridize the framework with an electrode, which allows the investigation of redox process in 25 the pores.

Although the judicious choice of metal ion and organic linker provides the redox activity within PCP frameworks ${ }^{8}$, the redox reaction often changes the coordination environment of metal ions, thus leading to destruction of the framework. One way to 30 overcome the issues is to construct the framework with stable ligands for the redox reaction. In this context, 1,1' ferrocenedicarboxylate $(\mathrm{Fcdc})$ is an excellent candidate because it contains the stable ferrocene moiety and two carboxylate coordination sites ${ }^{9}$. Some research groups have reported on the 35 syntheses of ferrocene-based coordination polymers ${ }^{10}$, but there are only a few reports of the solid-state electrochemical properties of coordination polymers containing the Fcde ligand ${ }^{11}$.

Recently we reported on a series of two-dimensional (2D) PCPs, so-called coordination polymers with an interdigitated 40 structure (CID), of which the three components, namely the metal ions, $V$-shaped dicarboxylate ligands, and diamine pillar ligands, participate in the construction ${ }^{12}$. Their porous properties and chemical functionalities can be easily modulated by varying the components. Although there is a limit to the angle of two 45 carboxylates in the $\mathrm{V}$-shaped ligand in the range $118^{\circ}-152^{\circ}$, the rotational freedom of the ferrocenyl moiety enables the ligand to mimic the V-shape, thus providing CID frameworks with stable redox properties.
Here we report the rational synthesis of ferrocene-based CID ${ }_{50}$ frameworks by incorporating different diamine pillar ligands. The length of the pillar ligand determines the configuration of the $2 \mathrm{D}$ sheets, resulting in different thermal stabilities. The electrochemical properties were elucidated by the immobilization of these crystals on gold electrodes.

55 A coordination framework of
$\left\{[\mathrm{Zn}(\mathrm{Fcdc})(\mathrm{bpy})]^{\bullet}(\mathrm{DMF})_{0.5}(\mathrm{MeOH})_{0.5}\right\}_{n} \quad($ 1 $\supset$ solvents $) \quad$ was synthesized via the reaction of $\mathrm{Zn}\left(\mathrm{NO}_{3}\right)_{2} \bullet 6 \mathrm{H}_{2} \mathrm{O}, \mathrm{H}_{2} \mathrm{Fcdc}$ and bpy in a $\mathrm{DMF} / \mathrm{MeOH}$ solution at $353 \mathrm{~K}$ (bpy $=4,4$ '-bipyridyl). As shown in Fig. 1a and $\mathrm{b}$, the $\mathrm{Zn}$ ion has a distorted octahedral ${ }_{60} \mathrm{~N}_{2} \mathrm{O}_{4}$ geometry; it is coordinated by two bpy molecules at the axial positions, one chelating carboxylate of Fcdc and two other monodentate caroboxylates of Fcdc in the equatorial plane. The coordination of Fcdc ligands to the $\mathrm{Zn}$ ions constructed a onedimensional (1D) chain structure as shown in Fig. 1a, followed ${ }_{65}$ by the linkage of the adjacent chains through bpy in the axial positions, leading to the formation of a $2 \mathrm{D}$ sheet. Alternatively assembled are two types of sheet structures, sheets A and B, which are mirror images of each other. It should be noted that the length of bpy $(7.1 \AA)$ is too short to form the interdigitation 70 because of the bulkiness of the ferrocenyl moiety (the distance between cyclopentadienyl rings is $6.8 \AA$ ), compared with the phenyl ring, seen in the reported CID structure. Therefore, the noninterdigitation between the sheets provided 1D channels with a window size of $4.4 \times 6.0 \AA^{2}$ (Fig. 2a-b, Fig. S1).

75 Elongation of the pillar ligands from bpy to $\mathrm{dpb}$ or dpndi created a space between the 1D chains and allowed them to form (a)

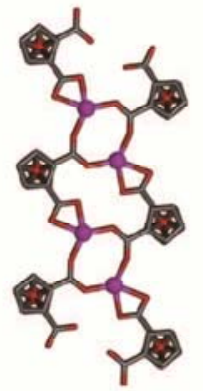

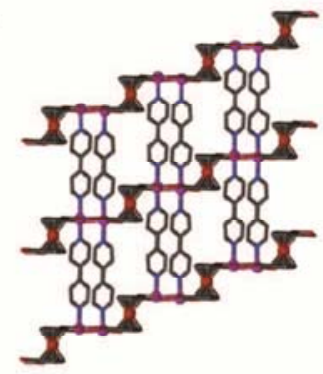

Fig. 1 Crystal structures of (a) the 1D chain structure composed of $\mathrm{Zn}$ ions and Fcdc, and (b) the sheet structure of 1. Gray, blue, red, orange, and purple are $\mathrm{C}, \mathrm{N}, \mathrm{O}, \mathrm{Fe}$ and $\mathrm{Zn}$, respectively. The hydrogen atoms and guest molecules are omitted for clarity. 


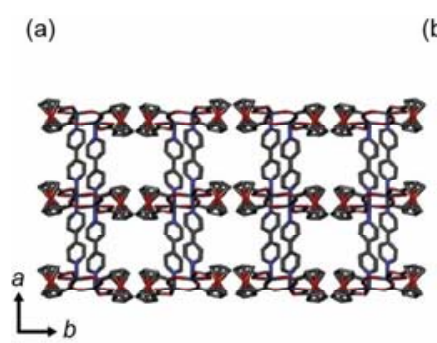

(b)

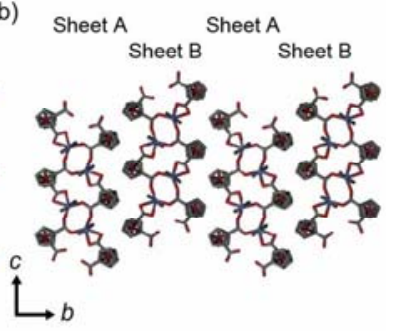

(c)

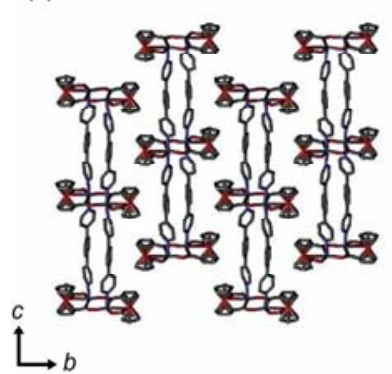

(e)

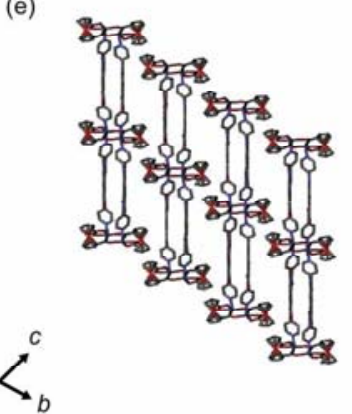

(d) Sheet A Sheet B Sheet A Sheet B

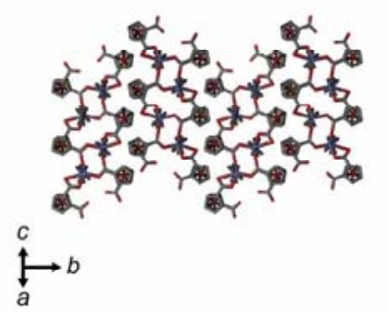

(f)
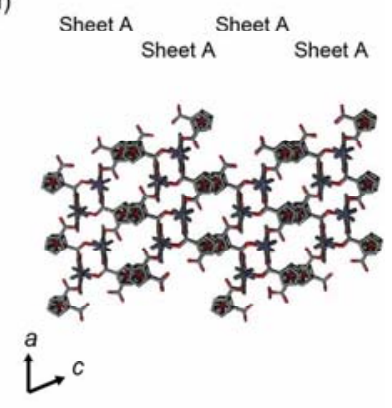

Fig. 2 Crystal structures showing (a) the side view, (b) the top view of assembled structure of $1 \supset$ solvents, (c) the side view, (d) the top view of assembled structure of $2 \supset$ solvents, (e) the side view, (f) the top view of assembled structure of $3 \supset$ solvents.

the interdigitation $(\mathrm{dpb}=1,4-\mathrm{di}($ pyridin-4-yl)benzene, $\mathrm{dpndi}=$ $N, N^{\prime}$-di(4-pyridyl)-1,4,5,8-naphthalenetetracarboxydiimide).

These analogous frameworks were synthesized by the solvothermal reaction of $\mathrm{Zn}\left(\mathrm{NO}_{3}\right)_{2} \cdot 6 \mathrm{H}_{2} \mathrm{O}$ with $\mathrm{H}_{2} \mathrm{Fcdc}$ and dpb or 5 dpndi in a $\mathrm{DMF} / \mathrm{MeOH}$ solution: $\left\{[\mathrm{Zn}(\mathrm{Fcdc})(\mathrm{dpb})] \cdot(\mathrm{DMF})_{0.5}(\mathrm{MeOH})_{0.5}\right\}_{n} \quad$ (2つsolvents) or $\left\{[\mathrm{Zn}(\mathrm{Fcdc})(\mathrm{dpndi})] \cdot(\mathrm{DMF})_{0.5}(\mathrm{MeOH})_{0.5}\right\}_{n} \quad$ (3つsolvents), respectively. Although the compound 2 formed the alternative assembly of sheet structures as seen in $\mathbf{1}$, only one type of $2 \mathrm{D}$ 10 sheet (sheet A) was found in the compound 3. The expansion of the interchain distance in $\mathbf{2}$ and $\mathbf{3}$ resulting from the incorporation of the longer pillar ligands (dpb $(11.4 \AA)$ or dpndi $(15.5 \AA)$ ) enables the 2D sheets to form the interdigitation. Whereas the 1D channels with a window size of $4.4 \times 4.9 \AA^{2}$ extend along the $c$ 15 axis in compound 2 , the 1D channels with a window size of $4.8 \times$ $4.5 \AA^{2}$ runs along the $a$ axis in compound 3 (Fig. S1-S3).

Thermogravimetric analysis indicated that $\mathbf{1}, \mathbf{2}$ and $\mathbf{3}$ released the guest molecules up to $200{ }^{\circ} \mathrm{C}$ (Fig. S4). Although 1 started to decompose around $250{ }^{\circ} \mathrm{C}, 2$ and 3 were stable up to $350{ }^{\circ} \mathrm{C}$. The 20 difference in the collapse temperature between 1, 2 and $\mathbf{3}$ isprobably because of the interdigitation of the 2D sheets in 2 and 3, which lends further thermal stability to the frameworks.

$\mathrm{X}$-ray powder diffraction (XRD) analysis of the evacuated

frameworks was carried out to confirm the stability of the open 25 structures in the absence of guest molecules. All the compounds retained their crystallinity, as shown in Figs S5-7. Adsorption measurements of ferrocene-based PCPs were performed for $\mathrm{CO}_{2}$, $\mathrm{N}_{2}$, and $\mathrm{O}_{2}$, as shown in Fig. S8-10. The adsorption isotherms of all compounds showed a Type I steep uptake for $\mathrm{CO}_{2}$ at the low30 pressure region, indicating the preservation of the ordered porous structure, but no eventual uptake for $\mathrm{N}_{2}$ and $\mathrm{O}_{2}$. Generally, PCPs preferentially adsorb $\mathrm{CO}_{2}$ over other small gases because of its small kinetic diameter ${ }^{13}$.

To date, the redox properties of coordination polymers 35 containing ferrocenes have been reported after either dissolving the crystals in solvent or by depositing the crystals on a working electrode. In both cases, however, it is very difficult to elucidate the redox property of the framework itself. These methods most likely led to the determination of the electrochemical activity of 40 the solute species (soluble oligomers or metal complexes) ${ }^{14}$. To overcome this issue and to determine the redox properties of the PCPs themselves, we immobilized the crystals of ferrocene-based PCPs on gold electrodes.

A gold substrate was placed in the reaction solution for four 45 days to grow the PCP crystals directly on the surface, in a perpendicular fashion to avoid coating by sedimentation ${ }^{15}$. The

(a)

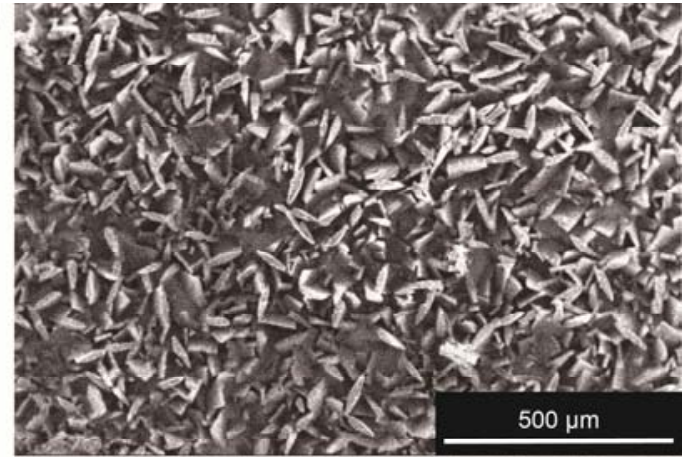

(b)

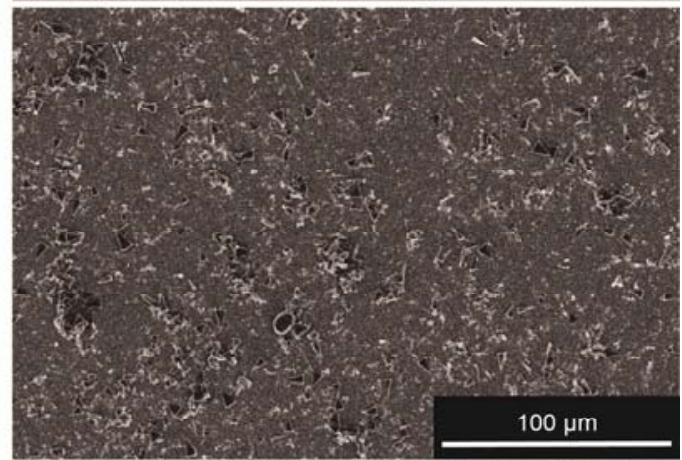

(c)

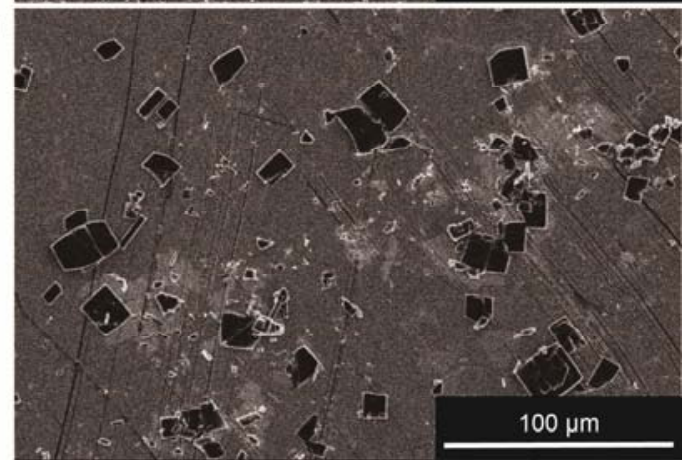

Fig. 3 SEM images of a) 1 b) 2, c) 3 on Au substrates 
(a)

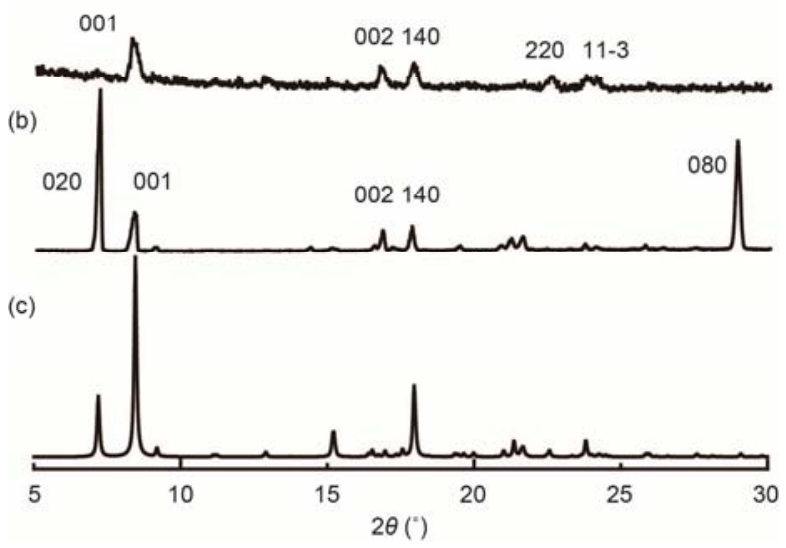

Fig. 4 XRD patterns of a) in-plane diffraction, b) out-of-plane diffraction of $\mathbf{1} / \mathrm{Au}, \mathrm{c}$ ) simulation of $\mathbf{1}$.

substrates were rinsed with DMF and dried in air. The plate-like crystals of $\mathbf{1}$ were densely grown on the electrode surface, whereas the crystals of $\mathbf{2}$ and $\mathbf{3}$ partially covered the substrates (Fig.3). The low solubility of the diamine ligands, dpb and dpndi, 5 most likely prevented the dense growth of $\mathbf{2}$ and $\mathbf{3}$.

XRD results of the substrate samples revealed that crystals were preferentially oriented on the substrates (Fig. 4 and Figs S11-14). The out-of-plane XRD scans of $\mathbf{1}$ and $\mathbf{3}$ on the gold electrodes (denoted as $\mathbf{1} / \mathrm{Au}$ and $\mathbf{3} / \mathrm{Au}$ ) demonstrated the presence 10 of a preferentially oriented crystalline material perpendicular to 020 and 011 respectively. The oriented crystal growth of $\mathbf{1}$ and $\mathbf{3}$ on the substrates can be explained by the coordination bond of carboxylates to the gold atoms. Together with the in-plane data, the PCP crystals of $\mathbf{1}$ and $\mathbf{3}$ were successfully immobilized on the 15 gold electrodes. Compound $\mathbf{2}$ on the gold electrode (denoted as 2/Au) showed rather weak diffraction because of the low crystallinity on the substrate.

The electrochemical behavior of $\mathbf{1} / \mathrm{Au}$ was investigated by cyclic voltammetry $(\mathrm{CV})$ in $\mathrm{CH}_{2} \mathrm{Cl}_{2}$ solution with $0.1 \mathrm{~mol} \mathrm{~L}{ }^{-1} n$ $20 \mathrm{Bu}_{4} \mathrm{NBF}_{4}$ as electrolyte. A reversible redox wave was observed at $0.95 \mathrm{~V}$. It was assigned to a Ferrocene/Ferrocenium cation in the PCP crystals (Fig. 5). Compared with the redox potential of $\mathrm{H}_{2} \mathrm{Fcdc}$ in $n-\mathrm{Bu}_{4} \mathrm{NBF}_{4}$ solution $(0.88 \mathrm{~V})$, that of $\mathbf{1} / \mathrm{Au}(0.95 \mathrm{~V})$ is shifted to a more positive potential (Fig. 5a and Table 1). The 25 reason for this is the electron-withdrawing property of the carboxylates from the cyclopentadienyl rings and the coordination bond between carboxylate and $\mathrm{Zn}$ ions ${ }^{16}$. Unfortunately, 2/Au and 3/Au did not show clear CV profiles, probably because of the low density of crystals on the electrodes.

30 A negative shift of the redox potential was observed $(0.78 \mathrm{~V})$ when changing the electrolyte from $n-\mathrm{Bu}_{4} \mathrm{NBF}_{4}$ to $n-\mathrm{Bu}_{4} \mathrm{NNO}_{3}$, which suggests that $\mathrm{NO}_{3}{ }^{-}$forms the stronger ion pair with the positively charged oxidized compounds of ferrocenium (Table 1). This can be explained by the smaller ionization energy of $\mathrm{NO}_{3}{ }^{-}$ 35 resulting in a higher degree of ion-pair formation ${ }^{17}$.

It is interesting that the peak currents show a linear dependence on the square roots of the scan rate, as shown in Fig. $5 \mathrm{~b}$. The linearity in the plots indicates that the charge transfer in the redox process is controlled by the diffusion of charges in the ${ }_{40}$ PCPs as described by the empirical Randles-Sevcik equation ${ }^{18}$. (a)

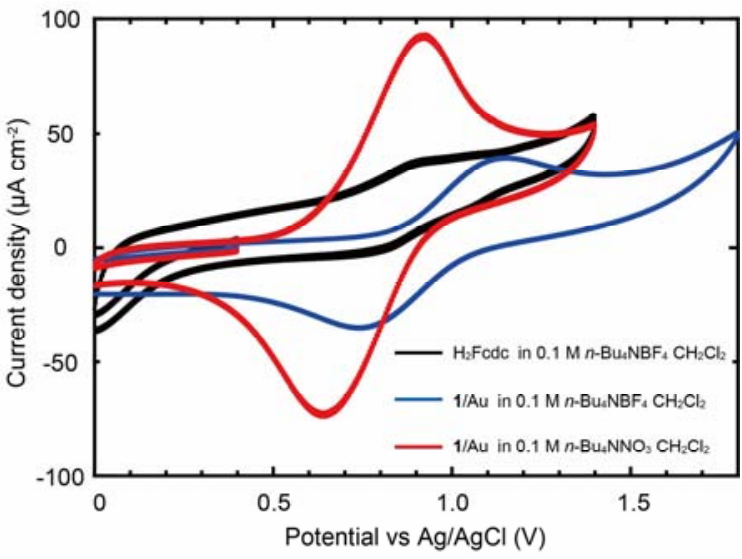

(b)

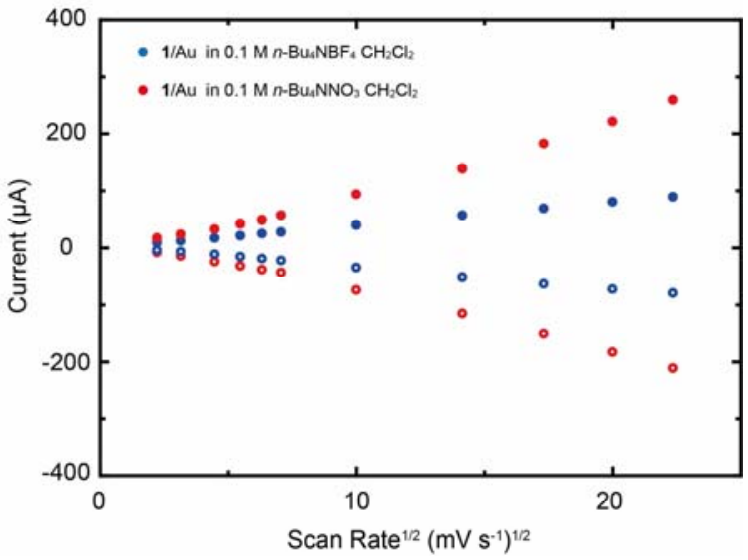

Fig. 5 (a) Cyclic voltammograms of $\mathrm{H}_{2} \mathrm{Fcdc}$ and 1 at $100 \mathrm{mV} / \mathrm{s}$ scan rates. The dispersed $\mathrm{H} 2 \mathrm{Fcdc}$ in $\mathrm{CH}_{2} \mathrm{Cl}_{2}$ was deposited onto the gold electrode. The current intensity of $\mathrm{H} 2 \mathrm{Fcdc}$ is magnified twice for clarify. (b) Dependence of peak currents on scan rates. Closed and open circles show oxidation and reduction, respectively.

Table. 1 Electrochemical data of $\mathbf{1}$ and Fcdc on an Au substrate at $100 \mathrm{mV} / \mathrm{s}$ scan rates

$\begin{array}{ccccc}\text { compounds } & \begin{array}{c}E_{1 / 2}{ }^{[\mathrm{a}]} \\ (\mathrm{V})\end{array} & \begin{array}{c}\Delta E^{[\mathrm{b}]} \\ (\mathrm{V})\end{array} & \begin{array}{c}\Gamma^{[\mathrm{c}]} \\ \left(\mathrm{mol} \mathrm{cm}{ }^{-2}\right)\end{array} & \text { electrolytes } \\ \mathrm{H}_{2} \mathrm{Fcdc} & 0.88 & 0.099 & - & n-\mathrm{Bu}_{4} \mathrm{NBF}_{4} \\ \mathbf{1} / \mathrm{Au} & 0.95 & 0.412 & 6.82 \times 10^{-10} & n-\mathrm{Bu}_{4} \mathrm{NBF}_{4} \\ \mathbf{1} / \mathrm{Au} & 0.78 & 0.301 & 2.09 \times 10^{-9} & n-\mathrm{Bu}_{4} \mathrm{NNO}_{3}\end{array}$

[a] The half wave potential, $E_{1 / 2}=\left(E_{\mathrm{ox}}+E_{\mathrm{red}}\right) / 2$. [b] The difference of the oxidation potential and reduction potential, $\Delta E=$ $E_{\mathrm{ox}}-E_{\text {red. }}$ [c] Surface concentration of redox active species.

Since the PCP crystals are immobilized on the electrode surface, the current is most likely limited by the diffusion of counteranions in the pores ${ }^{17}$. The contribution of the solute species to the redox reaction could be ignored because there was 45 no dissolution of the Fcde ligands from the framework under the conditions used, as confirmed by the CV measurement of the residual solution. Therefore, the redox reaction observed here was subsequently attributed to the ferrocene moiety embedded into the framework.

50 In summary, we have demonstrated the redox reaction of ferrocene-based PCPs achieved by creating crystals on gold substrates. Although the crystals are immobilized on the substrate, 
the redox process is controlled by the diffusion of charges. The $\mathrm{CV}$ results were interpreted as the diffusion of counteranions into the channels. This results indicats that Fcdc ligand allows for the incorporation of the redox activity into PCP frameworks and 5 opens the way for their use in a wide range of electronic applications.

\section{Notes and references}

${ }^{a}$ Department of Synthetic Chemistry and Biological Chemistry, Graduate School of Engineering, Kyoto University, Katsura, Nishikyo-ku, Kyoto,

10 615-8510, Japan.E-mail: kitagawa@sbchem.kyoto-u.ac.jp; Fax: +81-75383-2732; Tel: +81-75-383-2733

${ }^{b}$ ERATO Kitagawa Integrated Pores Project, Japan Science and Technology Agency (JST), Kyoto Research Park bldg \#3, Shimogyo-ku, Kyoto,600-8815, Japan. E-mail: shuhei.furukawa@kip.jst.go.jp; Fax: 15 +81-75-325-3572; Tel: +81-75-322-4711

${ }^{c}$ Institute for Integrated Cell-Material Sciences, Kyoto University, Yoshida, Sakyo-ku, Kyoto, 606-8501, Japan

$\uparrow$ Electronic Supplementary Information (ESI) available: [details of any supplementary information available should be included here]. See 20 DOI: $10.1039 / \mathrm{b} 000000 \mathrm{x} /$

† Crystal data for 1 $\supset$ solvents: $\mathrm{C}_{22} \mathrm{H}_{16} \mathrm{FeN}_{2} \mathrm{O}_{4} \mathrm{Zn} \quad M_{\mathrm{w}}=493.61 \mathrm{gmol}^{-1}$, monoclinic, space group $P 2_{1} / c$, (\#14), $a=11.367(5) \AA, b=24.599(9) \AA, c$ $=9.050(4) \AA, \beta=112.970(5), V=2330.0(16) \AA^{3}, Z=4, T=223 \mathrm{~K}, \rho_{\text {calc }}$ $=1.407 \mathrm{gcm}^{-3}, \mu\left(\mathrm{MoK}_{\alpha}\right)=1.679 \mathrm{~cm}^{-1}, 5308$ reflections measured, 2538

25 observed $(I>2.00 \sigma(\mathrm{I})) 271$ parameters; $R_{1}=0.0763, \mathrm{w} R_{2}=0.2108, \mathrm{GOF}$ $=0.914$. CCDC 852944

Crystal data for 2つsolvents: $\mathrm{C}_{28} \mathrm{H}_{20} \mathrm{FeN}_{2} \mathrm{O}_{4} \mathrm{Zn} \quad M_{\mathrm{w}}=569.70 \mathrm{gmol}^{-1}$, monoclinic, space group $P 2_{1} / c$, (\#14), $a=9.072(6) \AA, b=21.526(12) \AA, c$ $=14.375(9) \AA, \beta=99.212(12), V=2771(3) \AA^{3}, Z=4, T=223 \mathrm{~K}, \rho_{\text {calcd }}=$ $301.365 \mathrm{gcm}^{-3}, \mu\left(\mathrm{MoK}_{\alpha}\right)=1.422 \mathrm{~cm}^{-1}, 6166$ reflections measured, 3789 observed $(I>2.00 \sigma(\mathrm{I})) 325$ parameters; $R_{1}=0.0792, \mathrm{w} R_{2}=0.2253$, GOF $=1.016$. CCDC 852945 .

Crystal data for $3 \supset$ solvents: $\mathrm{C}_{36} \mathrm{H}_{20} \mathrm{FeN}_{4} \mathrm{O}_{8} \mathrm{Zn} \quad M_{\mathrm{w}}=757.80 \mathrm{gmol}^{-1}$, triclinic, space group $P-1,(\# 2), a=8.940(5) \AA, b=12.349(6) \AA, c=$ 35 15.288(8) $\AA, \alpha=78.383(18), \beta=87.636(18), \gamma=87.59(2), \quad V=$ $1650.9(15) \AA^{3}, Z=2, T=223 \mathrm{~K}, \rho_{\text {calcd }}=1.524 \mathrm{gcm}^{-3}, \mu\left(\mathrm{MoK}_{\alpha}\right)=1.225$ $\mathrm{cm}^{-1}, 7192$ reflections measured, 3822 observed $(I>2.00 \sigma(\mathrm{I})) 451$ parameters; $R_{1}=0.0731, \mathrm{w} R_{2}=0.1885, \mathrm{GOF}=0.936 . \mathrm{CCDC} 852946$.

401 (a) O. M. Yaghi, M. O'Keeffe, N. W. Ockwing, H. K. Chae, M Eddaoudi and J. Kim, Nature, 2003, 423, 705; (b) S. Kitagawa, R. Kitaura and S. Noro, Angew. Chem. Int. Ed., 2004, 43, 2334; (c) G. Férey, C. Mellot-Dranznieks, C. Serre and F. Millange, Acc. Chem. Res., 2005, 38, 217; (d) S. Batten and R. Robson, Angew. Chem. Int.

45 Ed., 1998, 37, 1460; (e) U. Mueller, M. Schubert, F. Teich, H. Puetter, K. Schierle-Arndt and J. Pastré, J. Mater. Chem., 2006, 16, 626.

2 (a) M. Dincă, A. Dailly, Y. Liu, C. M. Brown, D. A. Neumann and J. R. Long, J. Am. Chem. Soc., 2006, 128, 16876; (b) S. Ma, D. Sun, J. M. Simmons, C. D. Collier, D. Yuan, and H. C. Zhou, J. Am. Chem. Soc., 2008, 130, 1012; (c) R. Matsuda, R. Kitaura, S. Kitagawa, Y. Kubota, R. V. Belosludov, T. C. Kobayashi, H. Sakamoto, T. Chiba, M. Takata, Y. Kawazoe, Y. Mita, Nature, 2005, 436, 238.

3 (a) B. Wang, A. P. Côté, H. Furukawa, M. O'Keeffe and O. M. Yaghi, Nature, 2008, 453, 207; (b) L. Alaerts, C. E. A. Kirschhock, M. Maes, M. A. van der Veen, V. Finsy, A. Depla, J. A. Martens, G. V. Baron, P. A. Jacobs, J. F. M. Denayer, and D. E. De Vos, Angew. Chem. Int. Ed., 2007, 46, 4293; (c) B. Chen, C. Liang, J. Yang, D S. Contreras, Y. L. Clancy, E. B. Lobkovsky, O. M. Yaghi, and S. Dai, Angew. Chem. Int. Ed. 2006, 45, 1390.

604 (a) M. D. Allendorf, C. A. Bauer, R. K. Bhakta and R. J. T. Houk, Chem. Soc. Rev., 2009, 38, 1330. (b) G. J. McManus, J. J. Perry IV, M. Perry, B. D. Wagner, and M. J. Zaworotko, J. Am. Chem. Soc., 2007, 129, 9094. (c) K. C. Stylianou, R. Heck, S. Y. Chong, J. Bacsa, J. T. A. Jones, Y. Z. Khimyak, D. Bradshaw and M. J. Rosseinsky, J. 65 Am. Chem. Soc., 2010, 132, 4119; (d) Y. Takashima, V. M. Martinez, S. Furukawa, M. Kondo, S. Shimomura, H. Uehara, M. Nakahama, K. Sugimoto, S. Kitagawa, Nature Commun., 2011, 2, 168.
5 (a) S. Takaishi, M. Hosoda, T. Kajiwara, H. Miyasaka, M. Yamashita, Y. Nakanishi, Y. Kitagawa, K. Yamaguchi, A. Kobayashi, and H. Kitagawa, Inorg. Chem., 2009, 48, 9048; (b) M. H. Zeng, Q. X. Wang, Y. X. Tan, S. Hu, H. X. Zhao, L. S. Long and M. Kurmoo, J. Am. Chem Soc., 2010, 132, 2561; (c) S. Shimomura, M. Higuchi, R Matsuda, K. Yoneda, Y. Hijikata, Y. Kubota, Y. Mita, J. Kim, M. Takata and S. Kitagawa, Nature Chem., 2010, 2, 633.

756 G. Férey, F. Millange, M. Morcrette, C. Serre, M. L. Doublet, J. M. Grenéche and J. M. Tarascon, Angew. Chem. Int. Ed., 2007, 46, 3259.

7 L. Yang, S. Kinoshita, T. Yamada, S. Kanda, H. Kitagawa, M Tokunaga, T. Ishimoto, T. Ogura, R. Nagumo, A. Miyamoto and M. Koyama, Angew. Chem. Int. Ed., 2010, 49, 5348.

${ }_{80} 8$ (a) H. R. Moon, J. H. Kim and M. P. Suh, Angew. Chem. Int. Ed., 2005, 44, 1261; (b) L. M. Rodriguez-Albelo, A. R. Ruiz-Salvador, A. Sampieri, D. W. Lewis, A. Gómez, B. Nohra, P. Mialane, J. Marrot, F. Sécheresse, C. Mellot-Draznieks, R. N. Biboum, B. Keita, L. Nadjo and A. Dolbecq, J. Am. Chem. Soc., 2009, 131, 16078; (c) Y.

85 Kobayashi, B. Jacobs, M. D. Allendorf and J. R. Long, Chem. Mater., 2010, 22, 4120.

9 (a) R. Horikoshi and T. Mochida, Eur. J. Inorg. Chem., 2010, 5355; (b) V. Chandrasekhar and R. Thirumoorthi, Dalton Trans., 2010, 39 2684; (c) L. Wang, X. Meng, E. Zhang, H. Hou, Y. Fan, J. Organomet. Chem., 2007, 692, 4367.

10 (a) M. Meilikhov, K. Yusenko and R. A. Fischer, J. Am. Chem. Soc., 2009, 131, 9644; (b) J. E. Halls, A. Hernán-Gómez, A. D. Burrows and F. Marken, Dalton Trans., 2011, Advance Article; (c) K. J. Wei, J. Ni and Y. Liu, Inorg. Chem., 2010, 49, 1834.

9511 Although some studies on electrochemical properties of Fcdc-based coordination polymers have been reported, the compounds were dissolved in solutions or no detailed experimental condition was described. (a) J. Yang, J. F. Ma, Y. Y. Liu, S. L. Li and G. L. Zheng, Eur. J. Inorg. Chem., 2005, 2174; (b) Y. Xu, C. Ran, L. Zhu and Y. Fan, J. Coord. Chem., 2009, 62, 410.

12 (a) S. Horike, D. Tanaka, K. Nakagawa and S. Kitagawa, Chem. Commun. 2007, 3395; (b) D. Tanaka, K. Nakagawa, M. Higuchi, S. Horike, Y. Kubota, T. C. Kobayashi, M. Takata and S. Kitagawa, Angew. Chem. Int. Ed., 2008, 47, 3914 (c) K. Nakagawa, D Tanaka,

105 S. Horike, S. Shimomura, M. Higuchi and S. Kitagawa, Chem. Commun.2010, 4258.

13 D. N. Dybtsev, H. Chun, S. H. Yoon, D. Kim and Kimoon Kim, J. Am. Chem. Soc., 2004, 32, 126.

14 (a) B. Q. Liu, P. F. Yan, J. Zhang, P. Chen, G. M. Li, J. Organomet. Chem. 2010, 695, 2441; (b) J. Kühnert, T. Rüffer, P. Ecorchard, B Bräuer, Y. Lan, A. K. Powell and H. Lang, Dalton Trans., 2009, 4499.

15 (a) S. Hermes, F. Schröder, R. Chelmowski, C. Wöll and R. A Fischer, J. Am. Chem. Soc., 2005, 127, 13744; (b) O. Shekhah, H. Wang, S. Kowarik, F. Schreiber, M. Paulus, M. Tolan, C. Sternemann, F. Evers, D. Zacher, R. A. Fischer and C. Wöll, J. Am. Chem. Soc., 2007, 129, 15118; (c) E. Biemmi, C. Scherb and T. Bein, J. Am. Chem. Soc., 2007, 129, 8054.

15 D. Warren, H. Charles, D. Russell, J. Am. Chem. Soc., 1967, 89, 2316. 12016 (a) K. Uosaki, Y. Sato, H. Kita, Langmuir, 1991, 7, 1510; (b) M Péter, R. G. H. Lammertink, M. A. Hempenius and G. J. Vancsoion, Langmuir, 2005, 21, 5115.

17 K. Itaya, I. Uchida and V. D. Neff, Acc. Chem. Res., 1986, 19, 162.

18 M. Strømme, G. A. Niklasson and C. G. Granqvist, Solid State Commun., 1995, 96, 151. 
Graphical Abstract

A series of ferrocene-based porous coordination polymers was synthesized. The electrochemical properties were elucidated by the immobilization of the crystals on gold electrodes.

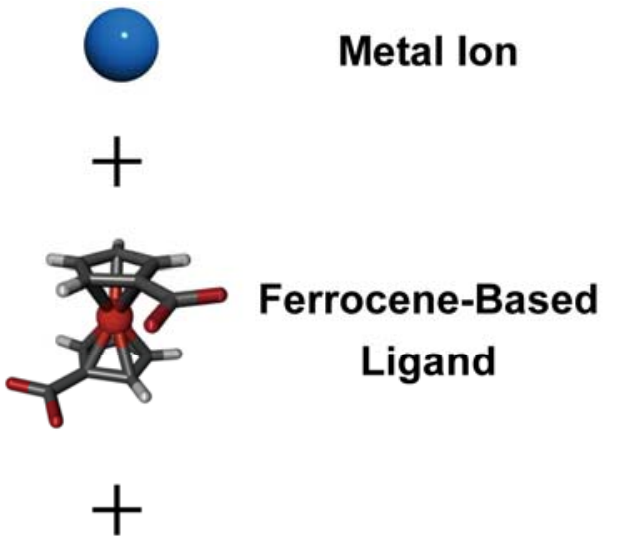

Pillar Ligand

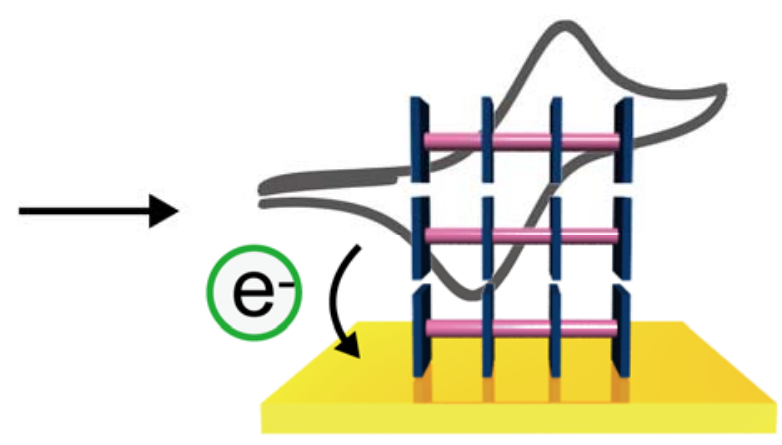

2D PCPs on Au Electrode 